\title{
Caring Of Health Officers in Administrative Services, Satisfaction of Inpatient Room Patients at the Muna Regency General Hospital Caring Petugas Kesehatan pada Pelayanan Administrasi, Kepuasan Pasien Ruang Rawat Inap di Rumah Sakit Umum Daerah Kabupaten Muna
}

Rasniah Sarumi, Elna Sari, Nur Yazlim

Politeknik Karya Persada Muna

\section{Abstract}

Baground: One form of service in the administration room is the caring behavior of health workers where the caring attitude will be intertwined with a relationship of mutual trust, compassion and honesty. Patients and their families will feel satisfied if the health services received are in accordance with the patient's expectations and can feel disappointed if the caring health workers received are not in line with their expectations so that patients will tend to choose health services that can provide good caring. The purpose of this study was to know the caring of health workers in administrative services on patient satisfaction in inpatients at the Muna Regency General Hospital. .

Method: The research design uses a cross sectional study approach involving a sample of 52 people. The data collection method used primary data and secondary data. Data analysis using Univariate and Bivariate analysis.

Results: there is a relationship between caring for health workers in administrative services to patient satisfaction in inpatients at the Muna Regency General Hospital with a value of 0,017.

Conclusions: there is a relationship between caring for health workers in administrative services to patient satisfaction in inpatients at the Muna Regency General Hospital.

Keywords: career, health workers, administrative services, patient satisfaction

\section{Abstrak}

Pendahuluan: Salah satu bentuk pelayanan diruangan administrasi adalah perilaku caring petugas kesehatan dimana sikap caring akan terjalin dengan adanya hubungan saling percaya, belas kasih dan kejujuran. Pasien maupun keluarga pasien akan merasa puas apabila pelayanan kesehatan yang diterima sesuai dengan harapan pasien dan dapat merasa kecewa bila caring petugas kesehatan yang diterima tidak sesuai dengan harapannya sehingga pasien akan cenderung memilih pelayanan kesehatan yang dapat memberikan caring dengan baik. Tujuan penelitian ini adalah diketahinya caring petugas kesehatan pada pelayanan administrasi terhadap kepuasan pasien di rawat inap Rumah Sakit Umum Daerah Kabupaten Muna.

Metode: Desain Penelitian menggunakan pendekatan Cross Sectional Study yang melibatkan sampel sebesar 52 orang. Metode pengumpulan data menggunakan data primer dan data sekunder. Analisis data menggunakan analisis Univariat dan Bivariat.

Hasil: ada hubungan caring petugas kesehatan pada pelayanan administrasi terhadap kepuasan pasien di rawat inap Rumah Sakit Umum Daerah Kabupaten Muna dengan nilai $\rho$ sebesar 0,017.

Kesimpulan: ada hubungan caring petugas kesehatan pada pelayanan administrasi terhadap kepuasan pasien di rawat inap Rumah Sakit Umum Daerah Kabupaten Muna

Kata kunci: Karir, petugas kesehatan, pelayanan administrasi, kepuasan pasien

\section{Alamat Korespondensi:}

Rasniah Sarumi

Email : rasniahsarumi14@gmail.com

DIII Administrasi Rumah Sakit, Politeknik Karya Persada Muna 


\section{PENDAHULUAN}

Pelayanan kesehatan menimbulkan persaingan antara penyedia pelayanan kesehatan termasuk rumah sakit dimana masalah kesehatan menjadi kebutuhan pokok bagi masyarakat sehingga rumah sakit dituntut untuk meningkatkan kualitas kesehatan tak terkecuali pelayanan kesehatan dibagian administrasi (Anonim, 2014).

Kegiatan administrasi sangat dibutuhkan oleh setiap instansti untuk menunjang kelengkapan informasi dalam hal pengambilan keputusan sehingga mempunyai pengaruh yang besar terhadap kepuasan pelanggan yakni pasien dan keluarga pasien. Oleh karena itu, rumah sakit selalu menjaga kepercayaan konsumen dengan meningkatkan kualitas pelayanan dimulai dari bagian administrasi (Assauri, 2017).

Secara global, perilaku caring petugas kesehatan sudah mulai membaik namun masih ada beberapa negara yang memiliki perilaku caring yang buruk. Berdasarkan hasil survey kepuasan pasien yang dilakukan oleh Riskesdas tahun 2018 bahwa beberapa rumah sakit menunjukkan 65,4\% pasien tidak puas terhadap pelayanan kesehatan yang didapatkan dengan mengambil sampe pasien rawat inap sebanyak 738 pasien di 23 rumah sakit (umum dan swasta) di lima kota besar di Indonesia mengeluh terhadap sikap petugas kesehatan yang kurang ramah, kurang simpatik dan kurang senyum (Riset Kesehatan Dasar, 2018).

Faktor manusia sebagai pemberi pelayanan terhadap publik dalam organisasi dianggap sangat menentukan dalam menghasilkan kualitas pelayanan kesehatan yakni kepuasan pasien dimana pasien dan keluarga pasien merupakan konsumen utama di rumah sakit (Thoha, 2017). Pasien bahkan keluarga pasien yang tidak merasa puas akan mengajukan komplain pada pihak rumah sakit. Komplain yang tidak segera ditangani akan mengakibatkan menurunnya kepuasan pelanggan terhadap kapabilitas pelayanan kesehatan dan akan memepengaruhi konsep bisnis dan manajemen rumah sakit (Assauri, 2017).

RSUD kabupaten Muna merupakan salah satu institusi pelayanan kesehatan yang ada di Sulawesi Tenggara. Jumlah kunjungan pasien rawat inap pada tahun 2017 sebanyak 4.895 kunjungan, tahun 2018 sebanyak 4.122 kunjungan dan tahun 2019 sebanyak 4.013 kunjungan. Jumlah kunjungan 3 bulan terakhir sebanyak 1.269 kunjungan. Berdasarkan wawancara awal pada 10 orang pasien di ruang rawat inap RSUD Kabupaten Muna didapatkan bahwa 5 orang mengatakan merasa puas dengan pelayanan rumah sakit dimana perawat teratur dalam mengontrol klien ke ruang perawatan sedangkan 5 orang lainnya mengatakan bahwa merasa tidak puas dengan pelayanan karena pasien merasa tidak diperdulikan dan kurangnya fasilitas di rumah sakit ikut berpengaruh dalam kurangnya caring pelayanan kesehatan dalam memberikan pelayanan.

Tujuan penelitian ini adalah untuk mengetahui hubungan Caring Petugas Kesehatan pada Pelayanan Administrasi terhadap Kepuasan Pasien Ruang Rawat Inap di Rumah Sakit Umum Daerah Kabupaten Muna tahun 2020

\section{METODE PENELITIAN}

Jenis penelitian yang digunakan adalah deskriptif analitik menggunakan pendekatan Cross Sectional Study pada 52 pasien. Teknik penarikan sampel menggunakan teknik cluster sampling. Variabel yang diteliti terdiri dari variabel terikat yaitu kepuasan pasien dan variabel bebas yaitu caring petugas kesehatan pada pelayanan administrasi. Analisis yang digunakan adalah uji chi square.

\section{HASIL PENELITIAN}

Hasil penelitian ini terdiri dari distribusi karakteristik responden, variabel penelitian dan hasil analisis bivariat.

Distribusi frekuensi responden berdasarkan karakteristik responden dapat dilihat pada tabel berikut. 
Tabel 1. Distribusi Frekuensi Responden Berdasarkan Karakteristik Responden

\begin{tabular}{ccc}
\hline Karakteristik Responden & $\mathbf{n}$ & \% \\
\hline Variabel 1 & & \\
\hline Umur (tahun & 37 & 71,2 \\
\hline $20-45$ & 15 & 28,8 \\
\hline $46-70$ & & \\
\hline Pendidikan terakhir & 16 & 30,8 \\
\hline S1 & 25 & 48,1 \\
SMA & 11 & 21,1 \\
SMP & & \\
\hline Pekerjaan & 4 & 7,7 \\
PNS & 2 & 3,8 \\
Honorer & 24 & 46,2 \\
Wiraswasta & 16 & 30,8 \\
IRT & 1 & 1,9 \\
Petani & 4 & 7,7 \\
Pedagang & 1 & 1,9 \\
Nelayan & 2020 &
\end{tabular}

Sumber : data primer, 2020

Tabel 1 menujukkan bahwa umur responden didominasi oleh responden berumur 30-40 tahun sebanyak 37 orang (71,2\%), pendidikan responden didominasi oleh SMA sebanyak 25 orang (48,1\%) dan pekerjaan responden di dominasi oleh wiraswasta sebanyak 24 orang (46,2\%).

Distribusi frekuensi responden berdasarkan variabel penelitian dapat dilihat pada tabel berikut.

Tabel 1. Distribusi Frekuensi Responden Berdasarkan Karakteristik Responden

\begin{tabular}{ccc}
\hline Karakteristik Responden & $\mathbf{n}$ & $\%$ \\
\hline Caring petugas kesehatan & & \\
\hline Baik & 20 & 38,5 \\
Kurang & 32 & 61,5 \\
\hline Kepuasan Pasien & & \\
\hline Puas & 16 & 30,8 \\
Tidak puas & 25 & 48,1
\end{tabular}

Sumber : data primer, 2020

Tabel 2 menunjukkan bahwa distribusi frekuensi karakteristik responden berdasarkan variabel penelitian caring petugas kesehatan didominasi oleh responden yang kurang sebanyak 32 orang (61,5\%) dan kepuasan pasien didominasi oleh pasien yang tidak puas sebanyak 25 orang $(48,1 \%)$.

Hasil analisis bivariat hubungan caring petugas kesehatan pada pelayanan administrasi terhadap kepuasan pasien ruang rawat inap di Rumah Sakit Umum Daerah Kabupaten Muna tahun 2020.

Tabel 3 Hubungan caring petugas kesehatan pada pelayanan administrasi terhadap kepuasan pasien ruang rawat inap di Rumah Sakit Umum Daerah Kabupaten Muna tahun 2020

\begin{tabular}{|c|c|c|c|c|c|c|}
\hline \multirow{3}{*}{ Variabel } & \multicolumn{5}{|c|}{ Kepuasan Pasien } & \multirow{3}{*}{$\begin{array}{c}\text { Hasil } \\
\text { Uji Statistik }\end{array}$} \\
\hline & Tidak Puas & \multicolumn{2}{|c|}{ Puas } & \multicolumn{2}{|c|}{ Total } & \\
\hline & (\%) & $n$ & (\%) & $n$ & (\%) & \\
\hline
\end{tabular}




\begin{tabular}{lccccccc} 
Kurang & 22 & 42,3 & 7 & 13,5 & 29 & 55,8 & $p$-Value $=0,017$ \\
Baik & 10 & 19,2 & 13 & 25 & 23 & 44,2 & \\
\hline
\end{tabular}

Sumber: data primer, 2020

Tabel 3 menunjukkan bahwa responden yang mendapatkan caring kurang dan merasa tidak puas sebanyak 22 orang $(42,3 \%)$ dan yang puas sebanyak 7 orang $(13,5 \%)$ sedangkan responden yang mendapatkan caring baik tetapi merasa tidak puas sebanyak 10 orang $(19,2 \%)$ dan yang merasa puas sebanyak 13 orang $(25 \%)$.

Hasil uji statistik Chi Square diperoleh $\rho$ value $=0,017$, karena nilai $\rho<0,05$ dengan derajat kemaknaan $\alpha=0,05$ maka hipotesis hipotesis alternatif diterima yang artinya ada hubungan caring petugas kesehatan pada pelayanan administrasi terhadap kepuasan pasien ruang rawat inap di Rumah Sakit Umum Daerah Kabupaten Muna tahun 2020

\section{PEMBAHASAN}

Hasil penelitian menunjukkan bahwa terdapat hubungan caring petugas kesehatan pada pelayanan administrasi terhadap kepuasan pasien ruang rawat inap di Rumah Sakit Umum Daerah Kabupaten Muna tahun 2020 berdasarkan hasil uji chi square diperoleh nilai $\rho$ value $=0,017$. Hal ini disebabkan oleh jika pasien mandapatkan perhatian, simpati dan tenaga kesehatan cepat tanggap terhadap segala jenis keluhan baik dari penampilan maupun jenis pelayanan terhadap pasien maka kepuasaan pasien terhadap caring tenaga kesehatan akan baik.

Hasil penelitian ini sejalan dengan penelitian yang dilakukan oleh Hafiz Sulaiman tahun 2017 menjelaskan bahwa ada hubungan antara kualitas pelayanan administrasi terhadap kepuasaan pasien di Klinik Pratama Hamidah Tanjung Morawa. Angka signifikan yang diperoleh sebesar 0,000, yaitu < 0,05 maka Ho di tolak dan Ha diterima (Hafiz, 2017).

Penelitian yang dilakukan oleh Isma Ishak tahun 2016 menunjukkan bahwa ada hubungan antara kinerja petugas pelayanan unit administrasi rawat jalan dengan kepuasan pasien yang mendapat pelayanan di unit administrasi rawat jalan RSUD Jailolo Kabupaten Halmahera Barat (Isma, 2016).

Suatu pelayanan dikatakan baik atau buruk tergantung pada tingkat kepuasan pengguna layanan yang didasarkan pada kualitas pelayanan itu sendiri. Kesehatan adalah suatu konsep yang telah sering digunakan tetapi sulit untuk dijelaskan artinya. Faktor yang berbeda menyebab kansulitnya mendefinisikan kesehatan, penyakit, dan kesakitan (Sugiharto, 2013).

Faktor kecepatan petugas dalam memberikan pelayanan dinilai masih kurang dan menyebabkan banyak pasien yang dating mengeluh karena lambannya kinerja petugas administrasi. Pasien yang dating lebih pagi mengeluhkan keterlambatan petugas, karena dengan demikian pasien menunggu lebih lama. Waktu dalam memberikan pelayanan juga cukup lama sehingga menimbulkan antrian yang cukup panjang, sementara setelah memberikan pelayanan kepada pasien, petugas juga tidak terlalu akrab dengan pasien sehingga menimbulkan kesan yang tidak menyenangkan bagi pasien yang datang.

Petugas administrasi juga kurang lebih lama disampaikan oleh pasien. Banyak pasien juga kemudian menyatakan tidak yakin dengan ketepatan petugas dalam memberikan pelayanan. Penelitian yang dilakukan oleh Hasbi tahun 2012 menunjukkan bahwa ada hubungan yang siknifikan antara kualitas pelayanan tenaga administrasi dengan kepuasan pasien.

\section{KESIMPULAN}

Penelitian ini dapat disimpulkan bahwa ada hubungan caring petugas kesehatan pada pelayanan administrasi terhadap kepuasan pasien di rawat inap Rumah Sakit Umum Daerah Kabupaten Muna. 
Disarankan kepada petugas pelayanan kesehatan agar menciptakan suasan ramah, tetap senyum kepada pasien dan keluarga pasien serta cepat tanggap terhadap keluhan pasien.

\section{DAFTAR PUSTAKA}

Anonim (2014) Keputusan Menteri Kesehatan RI, No. 1204/MENKES/SK/X/2014 tentang Persyaratan Kesehatan Lingkungan Rumah Sakit.

Assauri (2017) Customer Service yang Baik Landasan Pencapaian Customer Satisfaction dan Usahawan. Jakarta.

Hafiz, S. (2017) 'Pengaruh Pelayanan Administrasi Terhadap Kepuasan Pasien di Klinik Pratama Hamidah Tanjung Morawa"', Skripsi (Online), (Fakultas Ilmu Sosial dan Ilmu Politik, Universitas Bengkulu), pp. 94-103.

Isma, I. (2016) 'Hubungan antara kinerja petugas pelayanan unit administrasi rawat jalan dengan kepuasan pasien yang mendapat pelayanan di unit administrasi rawat jalan RSUD Jailolo Kabupaten Halmahera Barat', Jurnal Online, p. S2 Ilmu Kesehatan Masyarakat : Universitas Gajah M.

Riset Kesehatan Dasar (2018) Badan Penelitian dan Pengembangan Kesehatan.

Sugiharto, dkk (2013) Psikologi Pendidikan. Yogyakarta : UNY Press.

Thoha, M. (2017) Kepemimpinan Dalam Manajemen. Jakarta: PT. Raja Grafindo Persada. 